\title{
Long-term phenology of two North American secondary cavity-nesters in response to changing climate conditions
}

\author{
Tyler E. Wysner ${ }^{1}$ (D) A Andrew W. Bartlow ${ }^{1} \cdot$ Charles D. Hathcock ${ }^{2} \cdot$ Jeanne M. Fair ${ }^{1}$
}

Received: 15 March 2019 / Revised: 3 September 2019 / Accepted: 4 September 2019 / Published online: 11 October 2019

(C) The Author(s) 2019

\begin{abstract}
Wildlife populations can respond to changes in climate conditions by either adapting or moving to areas with preferred climate regimes. We studied nesting responses of two bird species, western bluebird (Sialia mexicana) and ash-throated flycatcher (Myiarchus cinerascens), to changing climate conditions (i.e., rising temperatures and increased drought stress) over 21 years in northern New Mexico. We used data from 1649 nests to assess whether the two species responded to changing climate conditions through phenological shifts in breeding time or shifts in nesting elevation. We also examined changes in reproductive output (i.e., clutch size). Our data show that western bluebirds significantly increased nesting elevation over a 19-year period by approximately $5 \mathrm{~m}$ per year. Mean spring temperature was the best predictor of western bluebird nesting elevation. Higher nesting elevations were not correlated with hatch dates or clutch sizes in western bluebirds, suggesting that nesting at higher elevations does not affect breeding time or reproductive output. We did not observe significant changes in nesting elevation or breeding dates in ash-throated flycatchers. Nesting higher in elevation may allow western bluebirds to cope with the increased temperatures and droughts. However, this climate niche conservatism may pose a risk for the conservation of the species if climate change and habitat loss continue to occur. The lack of significant changes detected in nesting elevation, breeding dates, and reproductive output in ash-throated flycatchers suggests a higher tolerance for changing environmental conditions in this species. This is consistent with the population increases reported for flycatchers in areas experiencing dramatic climate changes.
\end{abstract}

Keywords Phenology $\cdot$ Climate change $\cdot$ Birds $\cdot$ New Mexico $\cdot$ Clutch size $\cdot$ Nesting elevation

\section{Introduction}

There is evidence that climate change results in long-term, large-scale changes in ecosystems (McCarty 2001; Root et al. 2003; Stephens et al. 2016). Given currently unprecedented climate change, understanding the consequences of changes in climate conditions in the ecology and behavior of wildlife species is critical. This requires analyzing long-term relationships between species' traits and abiotic factors. Species can respond to changing climate conditions in

Communicated by: Matthias Waltert

Tyler E. Wysner

twysner@unm.edu

1 Biosecurity and Public Health, Los Alamos National Laboratory, PO Box 1663, Los Alamos, NM 87544, USA

2 Environmental Stewardship, Los Alamos National Laboratory, PO Box 1663, Los Alamos, NM 87544, USA different ways. Some species show niche conservatism and tend to track preferred climate regimes (Wiens and Graham 2005; Wiens et al. 2010). Species that cannot shift their distributions due to habitat degradation or geographic constraints and those that cannot adapt to the new climate conditions - or adapt too slowly - are at risk of extirpation or extinction (Devictor et al. 2008; Hoffmann and Sgrò 2011).

Wildlife populations can shift their geographic range to track their climatic niches (Tingley et al. 2012). Geographic range shifts can occur by moving to higher elevations in response to suboptimal conditions at lower elevations (Hoffmann and Sgrò 2011), increasing in latitude as areas become warmer (Chen et al. 2011), or tracking precipitation patterns (Crimmins et al. 2011). Elevational shifts in response to climate change have been reported in many bird species (Sekercioglu et al. 2008; Chen et al. 2011; Freeman et al. 2018). However, these species may be at risk of extinction if climate change continues to occur, given the imposed limitation of further range shifts in response to further changes. Moreover, although higher elevation habitats can act as 
refugia (Keppel et al. 2012), they can also be evolutionary traps. For example, shifting upslope is reported to result in higher predation risk (Hale et al. 2016).

Climate change can cause individuals to adjust behaviors through plasticity, such as shifting their breeding timing (Charmantier et al. 2008; Hoffmann and Sgrò 2011). Many studies have explored the effects of climate change on avian communities, specifically regarding shifts in reproductive phenology (Brawn 1991; Bradley et al. 1999; Dunn and Winkler 1999) and migration phenology (Cotton 2003), and show varying results. Some studies show that bird populations adjust phenology traits in response to local environmental changes (Bleu et al. 2017; Clermont et al. 2018). Large-scale studies and metaanalyses have shown a general trend in advancement in the breeding phenology of many bird species over time (Dunn and Winkler 1999; Torti and Dunn 2005; Gordo and Sanz 2006; Radchuk et al. 2019). Still, it is important to note that there may be a publication bias toward studies that show phenological advancement over time (Both et al. 2004).

Comparative studies that consider species behavior and lifehistory traits are crucial to predict responses to climate change. There is high variability in the observed responses of birds, making trends in species' responsiveness unpredictable (Stenseth et al. 2002; Carey 2009). Migratory behavior, including breeding site arrival and commencement of breeding, can be modified as a response to changes in the environment. The time between arrival and breeding can be influenced by the environment and food resources (Ahola et al. 2004). Sanz et al. (2003) showed that migratory pied flycatchers (Ficedula hypoleuca) did not advance their breeding in response to climate change to coincide with the peak in the food supply, possibly due to their late arrival to the breeding site. While resident species are also able to respond to environmental conditions to determine when they breed (Perrins 1970), migratory species may be under more stress from environmental change.

One method used to examine the effects of climate change on life-history traits is to monitor productivity by measuring clutch size, which has implications for population dynamics (Crick 2004). Studies conducted over elevation gradients report smaller clutch sizes and delayed breeding at higher elevations (Dillon and Conway 2015; Flousek et al. 2015; Boyle et al. 2016). Climate patterns, such as reduced precipitation in the months before the breeding season, can also cause deviations from optimal clutch sizes (Davies and Cooke 1983). However, if birds are moving upslope to track their climate niche, then the timing of breeding and clutch sizes should be unaffected by a change in elevation.

Whereas there are many observational studies on the effects of climate change on European passerine populations, particularly within the Paridae family (Sanz 2002; Visser et al. 2003; Whitehouse et al. 2013), few studies have been done on North American birds (Brown et al. 1999; Socolar et al. 2017), and even fewer on birds in southwestern North America (Brawn
1991; Torti and Dunn 2005). The effects of climate change are projected to have detrimental effects on bird populations in the southwest region. Bird species in this area are known to be particularly sensitive to habitat change, drought, and higher temperatures (Cruz-McDonnell and Wolf 2015; Bateman et al. 2016; Borgman and Wolf 2016; Fair et al. 2018). The Pajarito Plateau in northern New Mexico is predicted to become hotter and dryer in the future, like many areas of the southwest (Melillo et al. 2014). Additionally, high mortality of piñon pine trees at low elevations beginning in 2000 due to drought and subsequent bark beetle attacks resulted in declines in avian richness and abundance (Fair et al. 2018). Therefore, we need to better understand the potential impacts on wildlife populations in this region.

Western bluebirds (Sialia mexicana) and ash-throated flycatchers (Myiarchus cinerascens) are two common bird species in the southwest of North America. The species share breeding grounds but differ in their migratory behavior. Western bluebirds are short-distance migrants, if they migrate at all (Guinan et al. 2008), while ash-throated flycatchers are long-distance migrants (Butler et al. 2006). The differences in their migratory behavior and the availability of 21 years of nest box data for these species provide an excellent opportunity to analyze changes in bird reproductive phenology in response to warmer temperatures and rapid seasonal changes in the region.

The objective of this study was to document responses to climate change in populations of western bluebirds and ashthroated flycatchers on the Pajarito Plateau in northern New Mexico. We used a 21-year nest box dataset to investigate whether changes occurred in hatch date and nesting elevation. We tested two competing hypotheses: (1) bird populations have not shifted their nesting elevation but have advanced hatch date, and those birds nesting at higher elevations nest later than those nesting at lower elevations in the same year; and (2) bird populations have increased their nesting elevation over time but have not advanced their hatch dates. To determine whether the observed changes - or lack of them - had any reproductive costs for the studied species, we also investigated changes in clutch sizes. Because environmental conditions may affect the delay between arrival and breeding, we examined whether environmental factors influence hatch date for each species. We hypothesized that hatch date would advance in association with rising seasonal temperatures. We also hypothesized that lower precipitation levels in winter months before the breeding season, as well as higher drought indices, would cause breeding delays due to lack of resources.

\section{Methods}

\section{Study location}

This study was completed on the eastern flanks of the Jemez Mountains and the Pajarito Plateau and surrounding areas at 
Los Alamos National Laboratory (LANL) in northern New Mexico (35 52' 32" N $106^{\circ} 19^{\prime} 27^{\prime \prime} \mathrm{W}$ ). The predominant habitat of the Jemez Mountains is ponderosa pine (Pinus ponderosa) and piñon pine (Pinus edulis) forest. LANL occupies $103 \mathrm{~km}^{2}$ of the Pajarito Plateau, which is situated between approximately $1631 \mathrm{~m}$ and $3182 \mathrm{~m}$ (Oswald et al. 2016). One-seed juniper (Juniperus monosperma) and piñon pine trees make up the majority of the habitat on the Pajarito Plateau, which we refer to as piñon-juniper forest.

\section{Study species}

In this study, we analyzed 21 years of data for western bluebirds (hereafter referred to as "bluebirds") and ash-throated flycatchers (hereafter "flycatchers"). We collected and analyzed data obtained from a total of 1649 bluebird and flycatcher nests between the years 1997 and 2017, including 1378 bluebird nests and 271 flycatcher nests (Table 1). The sample sizes for each year for both species are listed in Table 1, as well

Table 1 Sample sizes (n), mean annual hatch date (Julian date), and standard deviation (SD) per year for western bluebird (Sialia mexicana) and ash-throated flycatcher (Myiarchus cinerascens) nests sampled on the Pajarito Plateau in northern NM, USA

\begin{tabular}{|c|c|c|c|c|}
\hline \multirow[b]{2}{*}{ Year } & \multicolumn{2}{|c|}{$\begin{array}{l}\text { Western } \\
\text { bluebird }\end{array}$} & \multicolumn{2}{|c|}{$\begin{array}{l}\text { Ash-throated } \\
\text { flycatcher }\end{array}$} \\
\hline & $n$ & $\begin{array}{l}\text { Julian date } \\
(\text { mean } \pm \text { SD })\end{array}$ & $n$ & $\begin{array}{l}\text { Julian date } \\
(\text { mean } \pm \text { SD })\end{array}$ \\
\hline 1997 & 19 & $162.95 \pm 17.96$ & 15 & $176.33 \pm 14.70$ \\
\hline 1998 & 57 & $166.72 \pm 16.35$ & 13 & $168.38 \pm 6.53$ \\
\hline 1999 & 64 & $164.59 \pm 10.70$ & 17 & $181.00 \pm 9.57$ \\
\hline 2000 & 25 & $170.32 \pm 15.42$ & 9 & $171.33 \pm 6.61$ \\
\hline 2001 & 21 & $161.57 \pm 16.87$ & 16 & $166.00 \pm 7.94$ \\
\hline 2002 & 34 & $165.59 \pm 17.98$ & 16 & $175.13 \pm 11.02$ \\
\hline 2003 & 59 & $149.12 \pm 22.33$ & 16 & $167.50 \pm 7.69$ \\
\hline 2004 & 47 & $151.70 \pm 15.72$ & 9 & $164.00 \pm 4.80$ \\
\hline 2005 & 70 & $158.16 \pm 19.37$ & 13 & $161.69 \pm 2.21$ \\
\hline 2006 & 62 & $159.39 \pm 14.30$ & 11 & $172.55 \pm 15.64$ \\
\hline 2007 & 73 & $157.18 \pm 17.61$ & 4 & $169.25 \pm 14.03$ \\
\hline 2008 & 90 & $171.06 \pm 12.22$ & 8 & $175.13 \pm 5.44$ \\
\hline 2009 & 103 & $156.09 \pm 13.81$ & 12 & $160.67 \pm 15.74$ \\
\hline 2010 & 43 & $163.53 \pm 9.05$ & 9 & $169.67 \pm 7.35$ \\
\hline 2011 & 51 & $161.59 \pm 14.81$ & 3 & $182.33 \pm 10.07$ \\
\hline 2012 & 45 & $149.91 \pm 16.32$ & 12 & $17.72 \pm 12.64$ \\
\hline 2013 & 35 & $166.06 \pm 13.00$ & 9 & $177.89 \pm 7.83$ \\
\hline 2014 & 75 & $158.67 \pm 15.57$ & 26 & $165.27 \pm 8.04$ \\
\hline 2015 & 164 & $161.91 \pm 14.34$ & 24 & $173.79 \pm 7.16$ \\
\hline 2016 & 129 & $165.56 \pm 9.70$ & 18 & $173.17 \pm 9.57$ \\
\hline 2017 & 112 & $160.62 \pm 13.05$ & 11 & $169.18 \pm 8.06$ \\
\hline Total & 1378 & & 271 & \\
\hline
\end{tabular}

as mean Julian hatch date for each year. Both species are secondary cavity-nesters that readily use nest boxes and share common breeding grounds. Flycatchers are strictly insectivorous, long-range migratory passerines (Butler et al. 2006). Breeding flycatchers in our study area migrate to central and South America. Bluebirds are omnivorous, and breeding bluebirds in our study area are short-distance migrants (Guinan et al. 2008). Bluebirds are commonly known to produce second clutches within a single breeding season, but this is variable (Jacobs et al. 2015). We found that our data only contained $4.3 \%$ second broods, and individual doubleclutches were not able to be identified as being from the same pair. Therefore, we considered all bluebirds' nests for the analyses. On the other hand, flycatchers rarely produce a second clutch during the breeding season in this area, and thus all flycatcher nests were included in the analyses.

\section{Nest boxes and data collection}

Over 500 wooden nest box sites were placed and continually monitored in the Jemez Mountains and on the Pajarito Plateau as part of an avian monitoring project initiated in 1997. Standard-sized commercially purchased nest boxes were used. Nest boxes had a hinged front face that opened outward, so observers could easily check nest occupancy and gather data on nestlings.

Nest boxes were placed in 49 different sampling locations (see Musgrave et al. 2019 for a map of the nest boxes) over an elevation gradient of more than $300 \mathrm{~m}$ (1892 to $2212 \mathrm{~m}$ ). Individual nest boxes were placed between 50 and $75 \mathrm{~m}$ apart and were primarily mounted to ponderosa pine and piñon pine trees approximately $2 \mathrm{~m}$ above the ground. The elevation of each box was recorded. Nest boxes that were deemed active beginning in May of every year were visited once a week until the observed hatch date, and then every 5 days to monitor for nest success. Data including species, hatch date, clutch size, and nest success were collected. Clutch size was defined as the number of eggs that were laid. Hatch date referred to the Julian date on which the first egg in the clutch hatched. Nestlings were banded after 10 days of age with a U.S. Bird Banding Laboratory numbered band. Data collectors acted in accordance with the Guidelines for the Use of Wild Birds in Research (Fair et al. 2010), and the project worked under an approved LANL Institutional Animal Care and Use Committee protocol. All New Mexico State and Federal Scientific Permits were obtained for all years of the project.

\section{Climate data}

Temperature and precipitation data specific to Los Alamos County, NM, were obtained from the Southern Regional Climate Center's Climate Information Data Portal (Louisiana State University 2018). As the annual temperature reference, 
we used the average spring (March-June) temperature. For precipitation, we used average spring (March-June) precipitation and average winter (November-February) precipitation. The annual Palmer Drought Severity Index (PDSI) was used to examine drought. PDSI considers both precipitation and temperature to estimate relative dryness. High PDSI values signify moist years, while low values indicate higher levels of drought. We obtained PDSI data specific to the Northern Mountains (Climate Division 2) in New Mexico from NOAA National Centers for Environmental Information (2018).

We used these four climate variables because they were a priori determined to be potentially important factors influencing the breeding phenology of both study species. We broke these up into spring and winter variables to tease apart whether spring conditions before and during the early part of the breeding season, or the conditions of the previous winter were better predictors of breeding and phenology. Spring conditions could directly affect the timing of nesting, hatch date, and clutch size, but conditions prior to the breeding season may affect other factors such as food abundance and affect reproductive traits (Nussey et al. 2005). Moisture availability, measured as PDSI, may have stronger effects on populations than temperature alone due to ecological interactions such as insect abundance (Fei et al. 2017; Imlay et al. 2018).

\section{Statistical analysis}

All statistical analyses were done in $\mathrm{R}$ version 3.6.1 (R Core Development Team 2018). We used the Mann-Kendall test to determine if temperature, precipitation, and PDSI changed significantly over the 21 -year study period. The MannKendall tests were performed using the package "Kendall" in R (McLeod 2011). For linear models (LM), normality of model residuals was assessed using Q-Q plots. Homogeneity of variances was assessed using Levene's test from the "car" package (Fox and Weisberg 2011). We only reported significant interactions between predictor variables and species, i.e., all interactions between species and other predictor variables that are not reported were not statistically significant at a significance level of $p=0.05$. When interactions were not significant, the interaction term was removed, and the results from the additive model were presented. When interactions were significant, species were analyzed separately to characterize relationships for each species.

We used data from each nest to test for changes over time (i.e., from 1997 to 2017) for hatch date (Table 1), clutch size, and nesting elevation and to test for relationships among these variables. Preliminary statistical analyses for hatch date over time showed that variances were not equal, and model residuals were not normal. However, an examination of the correlation plots of hatch date and year did not show any trend in either of the species. Therefore, we decided to use a linear mixed model (LMM) to test whether hatch date advanced over time. Species was specified as a factor in the model to test for differences in Julian hatch date between species. Boxes were spread out over several locations, which correspond to different canyons and watersheds on the Pajarito Plateau. Therefore, location was included as a random effect in this model.

For the rest of the analyses (unless otherwise stated), only nests with complete data were used due to missing clutch sizes (bluebirds $n=1263$; flycatchers $n=245$ ). Clutch size was not over-dispersed. Generalized linear mixed models (GLMM) with Poisson error distributions were used to assess changes in clutch size over time and to determine if hatch date predicted clutch size. In these models, species was set as a factor, and location was set as a random factor as described above. Mean values were used to plot the relationship between hatch date and clutch size.

To test for shifts in nesting elevation, we used two different subsets of the data. Each subset was used to correct for the fact that boxes were added at specific places during the 21-year study period. The first subset only included data from 1997 to 2008 because additional nest boxes were placed at higher elevations after that time (bluebird $n=552$; flycatchers $n=$ 132). Using only data from these early years decreased potential bias in nesting elevation. We removed locations that were abandoned before 2008. The other dataset included data spanning a 19-year period (1997 to 2015) collected from a subset of locations where nest boxes had neither been added nor removed during the study period (bluebird $n=641$; flycatcher $n=153$ ). In each case, LMs were used to evaluate nesting elevation over time with species added as a factor in the models. The interaction between species and elevation was added in the initial model. Variances were equal among groups and model residuals approximated normal distributions.

We used a LMM to determine if elevation predicts hatch date and a GLMM with a Poisson distribution to assess whether elevation is associated with clutch size. In both models, species was included as a factor with an interaction term between species and elevation. Year was set as a random effect. To test whether birds nesting at higher elevations breed later, years were also analyzed separately using LMs to determine the within-year effect of elevation on hatch date.

The following model selection procedure was performed twice to find the best environmental variables that predicted (1) hatch date of each species and (2) nesting elevation of bluebirds. We started with global models with the four environmental predictor variables, including interactions between spring temperature and spring precipitation. To avoid spurious model results, interactions between these variables and PDSI were not included in the global model. All predictors variables were standardized using the standardize function in the arm package to facilitate model convergence (Grueber et al. 2011; Gelman and $\mathrm{Su}$ 2018). Model selection was performed using the package MuMIn (Bartoń 2018). AICc values were 
compared to make sure that top models had a delta AICc value of 2 or greater (Burnham and Anderson 2002). Both $85 \%$ and $95 \%$ confidence intervals were used following the recommendations of Arnold (2010). Variables were considered significant if the $85 \%$ confidence intervals did not cross zero (Arnold 2010). The variables "year" and "location" were random effects in the model predicting hatch date. The variable "year" was a random effect in the model predicting nesting elevation.

\section{Results}

Mean spring temperature increased significantly over the 21year time period (Mann-Kendall Tau $=0.35, p=0.03$; Fig. 1). Mean spring precipitation (Tau $=-0.10, p=0.57$ ), mean winter precipitation $(\mathrm{Tau}=0.05, p=0.79)$, and PDSI (Tau $=$ $-0.18, p=0.26$ ) did not change significantly over the same period.

Hatch date did not advance over the 21-year time period for bluebirds and flycatchers (LMM year, estimate $=-0.009, \mathrm{SE}$ $= \pm 0.07, t=-0.132, p=0.90 ;$ Fig. 2 ). Hatch date significantly differed between bluebirds and flycatchers (LMM species, estimate $=-9.61, \mathrm{SE}= \pm 1.03, t=-9.38, P<0.01)$. On average, bluebirds hatched on the Julian day $161.0 \pm 15.7$ (mean \pm SD), i.e., June 10th, while flycatchers hatched on Julian day of $170.7 \pm 10.8$, i.e., June 19th.

Clutch size did not change significantly over time for bluebirds and flycatchers (GLMM estimate $=0.0009, \mathrm{SE}= \pm$ $0.002, z=0.462, p=0.64)$. Bluebirds had larger clutches than flycatchers (GLMM species, estimate $=0.174, \mathrm{SE}= \pm 0.036, z$ $=4.96, p<0.01$ ). Hatch date was a significant predictor of clutch size for both species, with earlier hatch dates corresponding to larger clutch sizes (GLMM hatch date, estimate $=-0.003, \mathrm{SE}= \pm 0.0008, z=-3.74, p<0.01 ;$ Fig. 3 ).

When combining data from nests of both species, nesting elevation increased significantly over time between 1997 and 2008 (LM year, estimate $=4.98, \mathrm{SE}= \pm 0.95, t=5.23, p<$

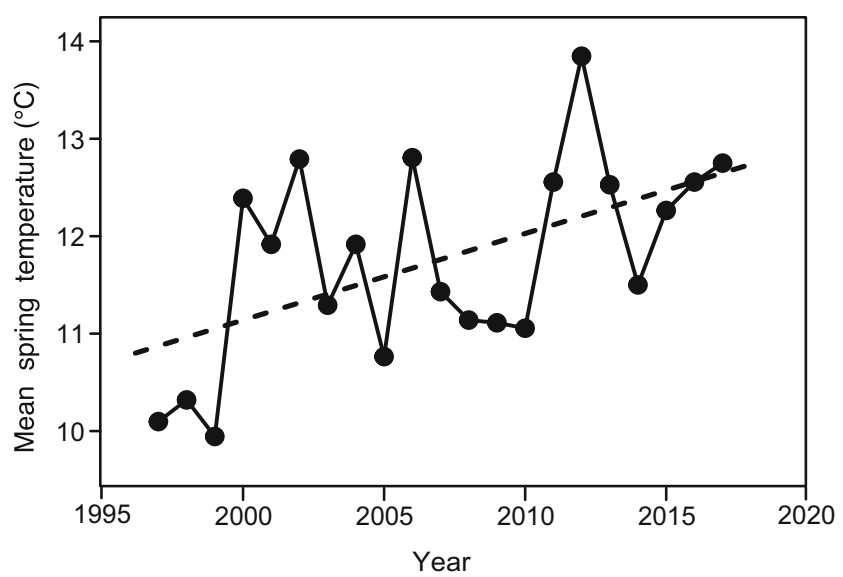

Fig. 1 Mean annual spring temperature in Los Alamos County, NM, USA from 1996 to 2017
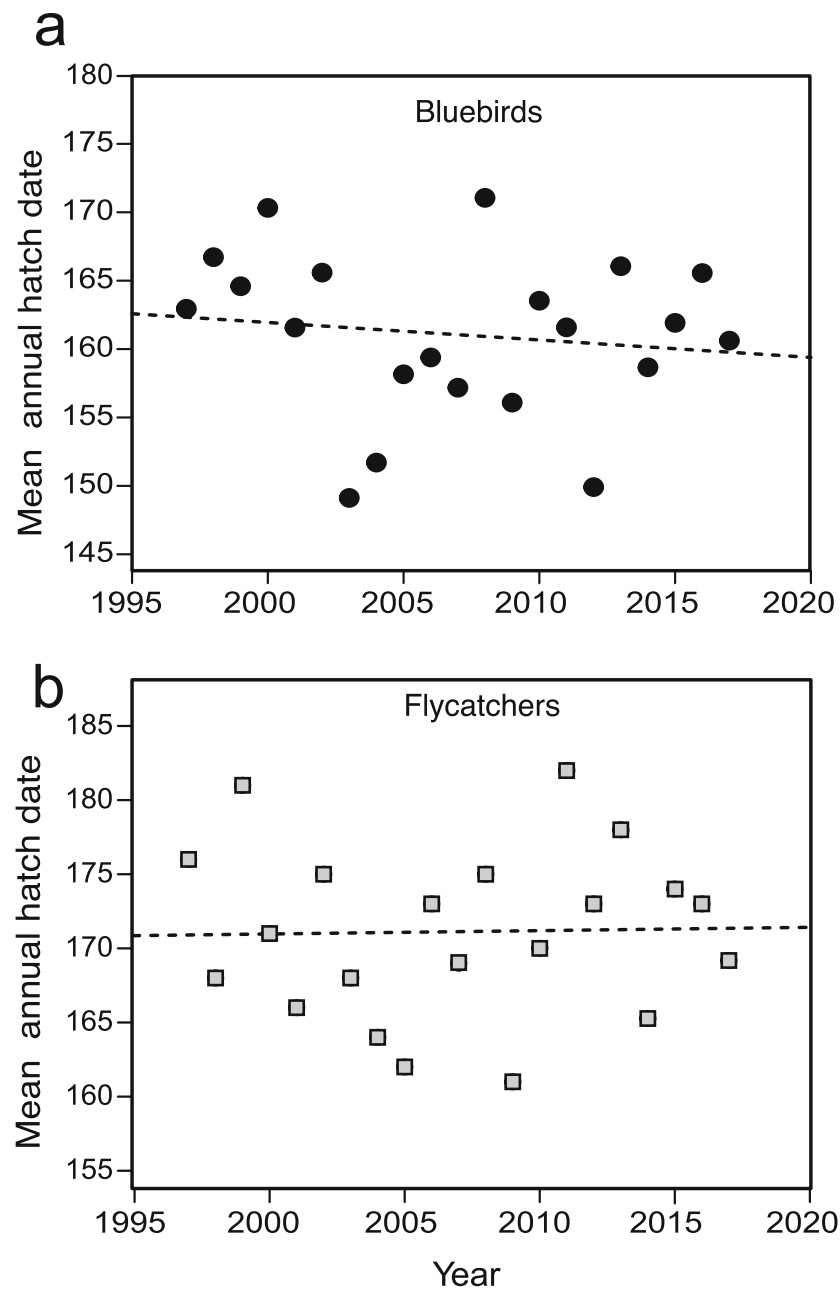

Fig. 2 Mean annual hatch date (Julian date) over time for a bluebirds (Sialia mexicana) and b flycatchers (Myiarchus cinerascens) from 1997 to 2017 on the Pajarito Plateau in northern NM, USA

0.01). The annual elevational change rate between 1997 and 2008 for both species combined was $5 \mathrm{~m}$ (bluebirds increased their nesting elevation by $5.2 \mathrm{~m}$ per year, and flycatchers increased it by $3.5 \mathrm{~m}$ ). Bluebirds nested c.a. $40 \mathrm{~m}$ higher than flycatchers during this period (LM species, estimate $=39.91$, $\mathrm{SE}= \pm 8.07, t=4.95, p<0.01)$. For the subset of data with boxes that spanned from 1997 to 2015, the interaction between year and species for predicting nesting elevation was statistically significant $(\mathrm{LM}$ year $*$ species, estimate $=3.70, \mathrm{SE}= \pm 1.34$, $t=2.77, p<0.01)$. Bluebirds ( $n=641$ nests) nested significantly higher over time (LM estimate $=4.32, \mathrm{SE} \pm 0.66, t=6.51, p$ $<0.01$; Fig. $4 \mathrm{a}$ ), with an increase of $4.3 \mathrm{~m}$ in nesting altitude per year. Flycatchers $(n=153$ nests) did not significantly change their nesting elevation over this time period (LM estimate $=$ $0.62, \mathrm{SE}= \pm 0.84, t=0.74, p=0.46$; Fig. $4 \mathrm{~b}$ ).

To determine if either more or fewer high-elevation or lowelevation nest boxes were used over time, we split up the 


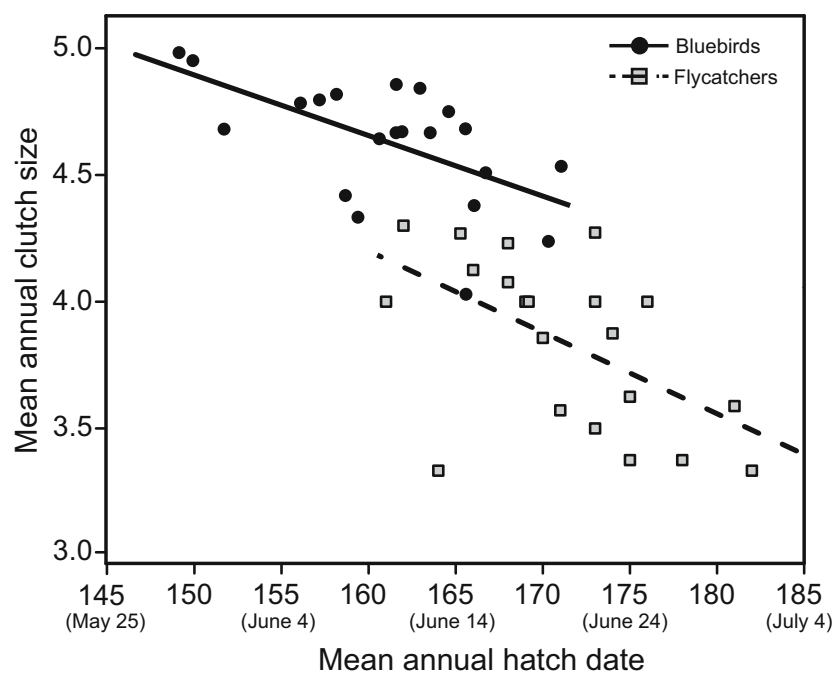

Fig. 3 The relationship between mean annual clutch size and mean annual hatch date for bluebirds (Sialia mexicana; black dots) and flycatchers (Myiarchus cinerascens; grey squares) from 1997 to 2017 on the Pajarito Plateau in northern NM, USA. Regression lines are the estimated effects of mean hatch date on mean clutch size from the linear mixed-effects model

dataset into early years (1997-2005) and later years (2006$2015)$. We calculated the mean number $( \pm$ SD) of occupied boxes (i.e., used by birds) per year located at low elevations (1890-2060 m) and high elevations (2060-2240 m). At low elevations, there were $23.11 \pm 13.43$ boxes occupied per year from 1997 to 2005 and $12.8 \pm 9.53$ boxes occupied per year from 2006 to 2017. At high elevations, there were $12.78 \pm$ 3.56 boxes occupied per year from 1997 to 2005 and $18.80 \pm$ 7.86 from 2006 to 2017. The number of nest boxes located at low elevations (Mann-Whitney $U$ test: $W=68, p=0.07$ ) and at high elevations (Mann-Whitney $U$ test: $W=24, p=0.09$ ) did not significantly differ between the two datasets (i.e., early and later years).

The best predictive model of nesting elevation for bluebirds was the full model without interactions. Spring temperature was the only variable found to be a significant predictor of nesting elevation (LMM: estimate [ $85 \%$ confidence intervals] $=37.9$ [13.1-63.2]). None of the other environmental variables were significant (i.e., confidence intervals included zero).

Nesting elevation was not a significant predictor of hatch date for bluebirds and flycatchers (LMM: estimate $=-0.003, \mathrm{SE}= \pm 0.003, t=-1.02, p=0.31)$ across years. Similarly, nesting elevation did not significantly affect clutch size for both species (GLMM: estimate < $0.01, \mathrm{SE}< \pm 0.001, z=1.05, p=0.29)$. When data from different years were separately analyzed, we found that bluebirds had earlier hatch dates at higher elevations in 1997 (LM: estimate $=-0.10, \mathrm{SE}= \pm 0.036, t=-2.57$, $p=0.02)$. For flycatchers, we found two years in which
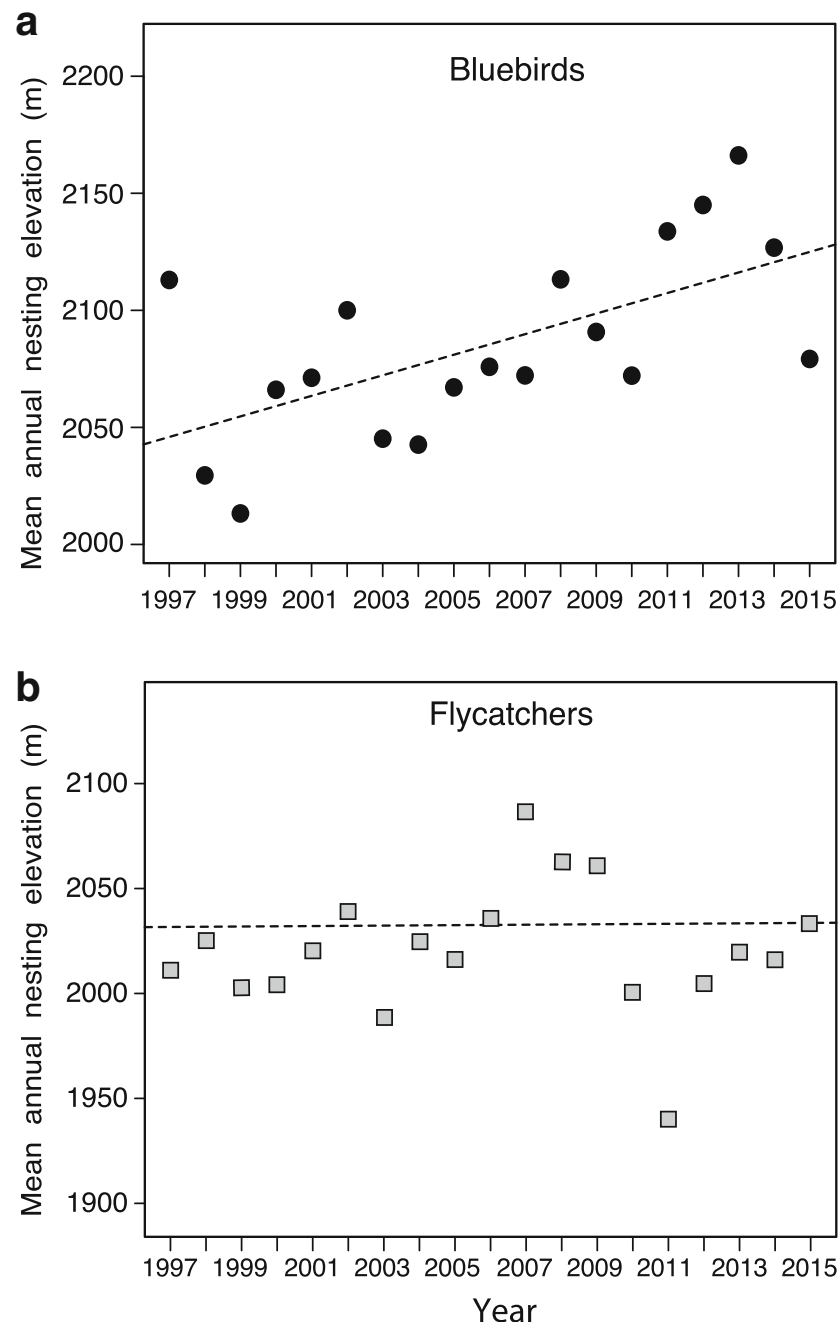

Fig. 4 Mean annual nesting elevation from 1997 to 2015 for a bluebirds (Sialia mexicana) and b flycatchers (Myiarchus cinerascens) on the Pajarito Plateau in northern NM, USA. Only locations that were monitored for the entire time period were included

birds nesting at higher elevations hatched earlier: 2004 (LM: estimate $=-0.07, \mathrm{SE}= \pm 0.027, t=-2.49, p=$ $0.04)$ and 2005 (LM: estimate $=-0.050, \mathrm{SE}= \pm 0.02, t$ $=-2.43, p=0.04$ ).

The best model predicting hatch date for each species included all four environmental variables and interactions between spring temperature and spring precipitation (Table 2). For bluebirds, hatch date was best predicted by PDSI and spring precipitation, (i.e., confidence intervals did not cross zero (Table 2). Higher PDSI values (i.e., wetter years) and less precipitation in the spring, was associated with later hatch dates. For flycatchers, PDSI, spring precipitation, and the interaction between spring precipitation and spring temperature were the best predictors of hatch date (Table 2). 
Table 2 Estimated parameters of the top models predicting hatch date for bluebirds (Sialia mexicana) and flycatchers (Myiarchus cinerascens) sampled on the Pajarito Plateau in northern NM, USA. Year and location were random effects in the models. . Bold values indicate variables whose confidence intervals do not include zero.

\begin{tabular}{lllllll}
\hline Species & Variable & Estimate & SE & $t$ value & $85 \%$ CI & \multicolumn{2}{c}{$95 \%$ CI } \\
\hline Bluebirds & Intercept & 161.30 & 1.44 & 111.7 & $159.50-163.10$ & $158.80-163.80$ \\
& Spring precipitation & -7.71 & $\mathbf{3 . 6 3}$ & $-\mathbf{2 . 1 2}$ & $-\mathbf{1 2 . 1 8}--\mathbf{3 . 2 4}$ & $-\mathbf{1 4 . 0 0 - - 1 . 4 7}$ \\
& Spring temperature & 0.26 & 3.04 & 0.085 & $-3.49-3.99$ & $-5.00-5.48$ \\
& Winter precipitation & -2.46 & 2.88 & -0.85 & $-5.94-1.20$ & $-7.38-2.57$ \\
& PDSI & $\mathbf{9 . 4 1}$ & $\mathbf{3 . 8 6}$ & $\mathbf{2 . 4 4}$ & $\mathbf{4 . 6 8}-\mathbf{1 4 . 2 0}$ & $\mathbf{2 . 7 9 - 1 6 . 1 0}$ \\
& Spring precipitation * spring temperature & -1.52 & 5.48 & -0.28 & $-8.40-5.17$ & $-11.00-7.87$ \\
Flycatcher & Intercept & 170.10 & 1.33 & 127.5 & $168.40-171.88$ & $167.6-172.50$ \\
& Spring precipitation & $-\mathbf{4 . 3 3}$ & $\mathbf{2 . 7 5}$ & $-\mathbf{1 . 5 8}$ & $-\mathbf{7 . 6 0}--\mathbf{0 . 7 1}$ & $-9.02-0.57$ \\
& Spring temperature & 2.01 & 2.57 & 0.78 & $-1.01-5.41$ & $-2.36-6.59$ \\
& Winter precipitation & -2.60 & 2.15 & -1.21 & $-5.34-0.04$ & $-6.37-1.11$ \\
& PDSI & $\mathbf{6 . 7 5}$ & $\mathbf{3 . 4 1}$ & $\mathbf{1 . 9 8}$ & $\mathbf{2 . 6 6 - 1 1 . 1 5}$ & $\mathbf{0 . 9 2}-\mathbf{1 2 . 8 0}$ \\
& Spring precipitation * spring temperature & $-\mathbf{1 3 . 5 0}$ & $\mathbf{4 . 3 6}$ & $-\mathbf{3 . 0 9}$ & $-\mathbf{1 8 . 7 5}--\mathbf{7 . 9 9}$ & $-\mathbf{2 0 . 9 3}-\mathbf{5 . 8 7}$ \\
\hline
\end{tabular}

$S E$ standard error, $C I$ confidence intervals, $P D S I$ Palmer Drought Severity Index

\section{Discussion}

The main objective of this study was to determine how bluebirds and flycatchers in northern New Mexico respond to changing climate conditions that include rising temperatures and increased drought stress. Using data from nest boxes collected over 21 years between 1997 and 2017, we found that bluebirds have not advanced their breeding but are nesting at higher elevations mainly in response to higher temperatures. Flycatchers have neither changed their breeding phenology nor shifted their nesting preferences to higher elevations.

We observed significant upslope shifts in nesting elevation in bluebirds over a 19-year period (1997 to 2015). The average elevation shift recorded in this species was $5 \mathrm{~m}$ per year. Probably because of this elevation shift in their breeding sites, we did not detect any changes in hatching date of this species. Higher nesting elevations were not correlated with hatch date. The shift to higher elevations for nesting was likely done to counter adverse nesting conditions at lower elevations, specifically warmer spring temperatures. These results are consistent with the hypothesis of climatic niche conservatism (Wiens et al. 2010), which states that species retain characteristics of the ancestral niche over time and space. Therefore, the climatic tolerance of bluebirds may not be high enough to face the rising temperatures in these areas, and thus may need to nest at higher altitudes. Previous studies have also documented a shift toward higher elevations in the breeding sites of other bird species in response to climate change (Sekercioglu et al. 2008; Chen et al. 2011; Maggini et al. 2011; Freeman et al. 2018). In addition, species that are year-round residents, like bluebirds, may be more likely to shift in elevation than migratory species (Tingley et al. 2012).

Our results show that spring temperature significantly predicted nesting elevation of bluebirds. However, other factors may have also played a role. High mortality of piñon pine trees at lower elevations began in 2000 due to drought and subsequent bark beetle attacks and resulted in declines in avian richness and abundance (Fair et al. 2018). Bluebirds are one of several species that rapidly declined in low-elevation habitat between 2003 and 2013 (Fair et al. 2018). The combined effects of increasing temperatures and high piñon pine mortality may have forced bluebirds to nest at higher elevations, especially if they could not breed earlier (Saracco et al. 2018). Although piñon pine mortality was only observed in a few locations where the studied nest boxes had been placed, our results could be the product of birds from tree-killed areas outside of the study sites nesting upslope. We found that bluebirds occupied fewer low-elevation nest boxes and occupied more nest boxes located at higher elevation sites over time. Even though there were no significant changes in nest box occupancy over time, these results suggest that bluebirds are shifting their range on the Pajarito Plateau, instead of expanding or contracting their range. Bluebirds are not advancing upslope while still occupying the same numbers of low elevation nest boxes (range expansion) or abandoning low elevation sites while not occupying more boxes upslope (range contraction).

Clutch sizes were similar throughout the 21-year study period for both bluebirds and flycatchers. This suggests that these species aremaximizing their reproductive investment by nesting in optimal habitats. For bluebirds, this is mediated by shifting their breeding locations, instead of nesting in suboptimal microhabitats (Dawson et al. 2011). Suboptimal microhabitats for bluebird breeding are presumably located at low elevations where temperatures are higher. As in other species, both bluebirds and flycatchers showed declines in clutch size throughout the breeding season (Lack 1947, 1948; Decker et al. 2012). However, clutch sizes of bluebirds were not influenced by the elevation of their nests. The timing of their breeding seems to have agreater effect on clutch size than elevation. 
Our results suggest that flycatchers are more tolerant to changing environmental conditions than bluebirds. Flycatchers did not increase their nesting elevation or advance their hatch date over the entire study period. We do not know why flycatchers showed patterns of upward elevational shifting between 1997 and 2008, but this pattern seems to be spurious and driven by the data of only one year (2007). Flycatchers nested approximately $40 \mathrm{~m}$ lower than bluebirds between 1997 and 2008 and 55 m lower between 1997 and 2015. Flycatcher clutch sizes did not change significantly over time. Furthermore, flycatcher populations have been reported to have increased across their range between 1966 and 2011 in areas affected by climate change (Sauer et al. 2013). Even though flycatchers are long-distance migrants, there seems to be no effect of mismatching food resources due to hatch dates since clutch sizes have remained constant over time. Our results follow the patterns observed regarding migratory species not shifting their ranges compared with non-migrants or shortdistance migrants (Tingley et al. 2012).

Nesting at higher elevations in any given year did not result in later hatch dates for either species. This was contrary to our hypothesis and contrasts with the results reported in other studies (Boyle et al. 2016). Birds can change their breeding phenology to track resource pulses (Visser et al. 2006; Both et al. 2009; Socolar et al. 2017). The lack of differences observed in hatch dates at different elevations within the same breeding season suggests that resources are similar throughout the elevation gradient. Similarly, resource peaks might not have shifted significantly over time. Resource peaks are sometimes uncoupled from increasing temperatures or changing conditions (Cleland et al. 2007).

Despite an increase in temperature in the study area over recent years, the effects of temperature variables on hatch date were small. This contrasts with the results of other studies that have found a seasonal temperature to effect breeding phenology (Vedder 2012; Whitehouse et al. 2013). Precipitation levels are also thought to affect the phenology and fitness of insectivorous birds (McKeller et al. 2013; Imlay et al. 2018). Great tits (Parus major) synchronize their breeding with the abundance of caterpillars to maximize food for their offspring (Visser et al. 2006). We found that bluebirds and flycatchers hatched earlier when there was more spring precipitation, and they hatched later when PDSI values were higher (i.e., when it was wetter). We are not entirely sure why there is a discrepancy in precipitation and PDSI. High precipitation events in the spring may cause birds to breed early, anticipating high food abundance (Ahumada 2001). High PDSI values indicate that conditions are relatively moist compared with normal. These rare moist periods are most likely caused by several months of precipitation prior to breeding rather than heavy precipitation events in the spring. In flycatchers, the interaction between spring temperature and spring precipitation was significant with a negative coefficient. As temperature increases, the negative coefficient of precipitation on hatch date decreases, meaning hatch dates become earlier.

Southwestern North America is particularly vulnerable to future climate change, and this could lead to further bark beetle attacks and tree mortality (Anderson-Teixeira et al. 2010). Future projections show that tree mortality in this system due to increasing drought and warmer temperatures will continue to alter habitats (Williams et al. 2010; McDowell and Allen 2015). Piñon pine and ponderosa habitats are extremely important for avian species richness and diversity (Kalies and Rosenstock 2013; Johnson et al. 2017; Fair et al. 2018). If the current response of bluebirds is to nest at higher elevations, there may be a time when individuals will no longer be able to move to higher elevations (Freeman et al. 2018). Lack of adaptation to climate change may result in continued range shifts and potential population declines (Williams et al. 2008; Freeman et al. 2018). Studying the plasticity and ability to adapt in response to changing climate conditions will help in understanding climate impacts on biodiversity and guide conservation efforts.

Acknowledgments We thank K. Burnett, K. Colestock, J. Foxx, D. Keller, A. Jacobs, L. Maestas, M. Musgrave, E. Phillips, E. Powell, R. Robinson, M. Salazar, S. Sherwood, A. Skinner, A. Smith, B. Thompson, and S. Whitaker for their assistance in the field from 1997-2017. We are grateful to $\mathrm{O}$. Myers for establishing the avian nest box monitoring network and R. Mirenda, L. Hansen, R. Ryti, and S. Reneau for continued support. We also thank Allison Chan for help with data analysis.

Funding information This research was funded by the Environmental Restoration Program through Los Alamos National Security, LLC, operator of the Los Alamos National Laboratory under Contract No. DEAC52-06NA25396.

\section{Compliance with ethical standards}

Conflict of interest The authors declare that they have no conflict of interest.

Research involving animals Data collectors acted in accordance with the Guidelines for the Use of Wild Birds in Research (Fair et al. 2010), and the project worked under an approved LANL Institutional Animal Care and Use Committee protocol.

Open Access This article is distributed under the terms of the Creative Commons Attribution 4.0 International License (http:// creativecommons.org/licenses/by/4.0/), which permits unrestricted use, distribution, and reproduction in any medium, provided you give appropriate credit to the original author(s) and the source, provide a link to the Creative Commons license, and indicate if changes were made.

\section{References}

Ahola M, Laaksonen T, Sippola K, Eeva T, Rainio K, Lehikoinen E (2004) Variation in climate warming along the migration route uncouples arrival and breeding dates. Glob Chang Biol 10:1610-1617 
Ahumada JA (2001) Comparison of the reproductive biology of two neotropical wrens in an unpredictable environment in northeastern Colombia. Auk 118:191-210

Anderson-Teixeira KJ, DeLong JP, Fox AW, Brese DA, Litvak ME (2010) Differential responses of production and respiration to temperature and moisture drive the carbon balance across a climatic gradient in New Mexico. Glob Chang Biol 17:410-424

Arnold TW (2010) Uninformative parameters and model selection using Akaike's Information Criterion. J Wildlife Manage 74:1175-1178.

Bartoń K (2018) MuMIn: Multi-Model Inference. R package version 1.42.1. https://CRAN.R-project.org/package $=$ MuMIn

Bateman BL, Pidgeon AM, Radeloff VC, VanDerWal J, Thogmartin WE, Vavrus SJ, Heglund PJ (2016) The pace of climate change vs. potential bird distributions and land use in the Unites States. Glob Chang Biol 22:1130-1144

Bleu J, Agnosti S, Biard C (2017) Nest-box temperature affects clutch size, incubation initiation, and nesting health in great tits. Behav Ecol 28:793-802

Borgman CC, Wolf BO (2016) The indirect effects of climate variability on the reproductive dynamics and productivity of an avian predator in the arid Southwest. Oecologia 180:279-291

Both C, Artemyev AV, Blaauw B, Cowie RJ, Dekhuijzen AJ, Eeva T, Enemar A, Gustafsson L, Ivankina EV, Järvinen A, Metcalfe NB, Nyholm NEI, Potti J, Ravussin PA, Sanz JJ, Silverin B, Slater FM, Sokolov LV, Török J, Winkel W, Wright J, Zang H, Visser ME (2004) Large-scale geographical variation confirms that climate change causes birds to lay earlier. Proc R Soc Lond B 271:16571662

Both C, van Asch M, Bijlsma RG, van den Burg AB, Visser ME (2009) Climate change and unequal phenological changes across four trophic levels: constraints or adaptations? J Anim Ecol 78:73-83

Boyle A, Sandercock B, Martin K (2016) Patterns and drivers of intraspecific variation in avian life history along elevational gradients: a meta-analysis. Biol Rev 91:469-482

Bradley NL, Leopold AC, Ross J, Huffaker W (1999) Phenological changes reflect climate change in Wisconsin. Proc Natl Acad Sci USA 96:9701-9704

Brawn JD (1991) Environmental effects on variation and covariation in reproductive traits of western bluebirds. Oecologia 86:193-201

Brown J, Li SH, Bhagabati N (1999) Long-term trend toward earlier breeding in an American bird: a response to global warming? Proc Natl Acad Sci USA 96:5565-5569

Burnham KP, Anderson DR (2002) Model selection and multimodel inference: a practical information-theoretic approach, 2nd edn. Springer-Verlag, New York

Butler LK, Rohwer S, Rogers M (2006) Prebasic molt and molt-related movements in ash-throated flycatchers. Condor 108:647-660

Carey C (2009) The impacts of climate change on the annual cycles of birds. Phil Trans R Soc B 364:3321-3330

Charmantier A, McCleery RH, Cole LR, Perrins C, Kruuk LE, Sheldon BC (2008) Adaptive phenotypic plasticity in response to climate change in a wild bird population. Science 320:800-803

Chen IC, Hill JK, Ohlemüller R, Roy DB, Thomas CD (2011) Rapid range shifts of species associated with high levels of climate warming. Science 333:1024-1026

Cleland EE, Chuine I, Menzel A, Mooney HA, Schwartz MD (2007) Shifting plant phenology in response to global change. Trends Ecol Evol 22:357-365

Clermont J, Réale D, Giroux JF (2018) Plasticity in laying dates of Canada Geese in response to spring phenology. Ibis 160:597-607

Cotton PA (2003) Avian migration phenology and global climate change. Proc Natl Acad Sci USA 100:12219-12222

Crick HQ (2004) The impact of climate change on birds. Ibis 146:48-56 Crimmins SM, Dobrowski SZ, Greenberg JA, Abatzoglou JT, Mynsberge AR (2011) Changes in climatic water balance drive downhill shifts in plant species' optimum elevations. Science 331:324-327
Cruz-McDonnell KK, Wolf BO (2015) Rapid warming and drought negatively impact population size and reproductive dynamics of an avian predator in the arid southwest. Glob Chang Biol 22:237-253

Davies JC, Cooke F (1983) Annual nesting productivity in snow geese: prairie droughts and arctic springs. J Wildl Manag 47:291-296

Dawson TP, Jackson ST, House JI, Prentice IC, Mace GM (2011) Beyond predictions: biodiversity conservation in a changing climate. Science 332:53-58

Decker K, Conway C, Fontaine J (2012) Nest predation, food, and female age explain seasonal declines in clutch size. Evol Ecol 26:683-699

Devictor V, Julliard R, Couvet D, Jiguet F (2008) Birds are tracking climate warming, but not fast enough. Proc R Soc B 275:2743-2748

Dillon K, Conway C (2015) Elevational gradient in clutch size of redfaced warblers. J Field Ornithol 86:163-172

Dunn PO, Winkler DW (1999) Climate change has affected the breeding date of tree swallows throughout North America. P R Soc B 266: 2487-2490

Fair JM, Paul E, Jones J (eds) (2010) Guidelines to the use of wild birds in research. Ornithological Council, Washington, D.C.

Fair JM, Hathcock CD, Bartlow AW (2018) Avian communities are decreasing with piñon pine mortality in the southwest. BiolConserv 226:186-195

Fei S, Desprez JM, Potter KM, Jo I, Knott JA, Oswalt CM (2017) Divergence of species responses to climate change. Sci Adv 3: e1603055

Flousek J, Telenský T, Hanzelka J, Reif J (2015) Population trends of central European montane birds provide evidence for adverse impacts of climate change on high-altitude species. PLoS One 10: e0139465

Fox J, Weisberg S (2011) An $\{\mathrm{R}\}$ Companion to applied regression, second edition. Sage, Thousand Oaks http://socserv.socsci. momaster.ca/jfox/Books/Companion

Freeman BG, Scholer MN, Ruiz-Gutierrez V, Fitzpatrick JW (2018) Climate change causes upslope shifts and mountaintop extirpations in a tropical bird community. Proc Natl Acad Sci USA 15:1198211987

Gelman A, Su Y (2018) arm: Data analysis using regression and multilevel/hierarchical models. R package version 1.10-1. https:// CRAN.R-project.org/package $=$ arm

Gordo O, Sanz JJ (2006) Climate change and bird phenology: a long-term study in the Iberian Peninsula. Glob Chang Biol 12:1993-2004

Grueber CE, Nakagawa S, Laws RJ, Jamieson IG (2011) Multimodel inference in ecology and evolution: challenges and solutions. J Evol Biol 24:699-711

Guinan JA, Gowaty PA, Eltzroth EK (2008) Western bluebird (Sialia mexicana), version 2.0. In: Poole AF (ed) The Birds of North America. Cornell Lab of Ornithology, New York. https://doi.org/ 10.2173/bna.510

Hale R, Morrongiello JR, Swearer SE (2016) Evolutionary traps and range shifts in a rapidly changing world. Biol Lett 12:20160003

Hoffmann AA, Sgrò CM (2011) Climate change and evolutionary adaptation. Nature 470:479-485

Imlay TL, Flemming JM, Saldanha S, Wheelwright NT, Leonard ML (2018) Breeding phenology and performance for four swallows over 57 years: relationships with temperature and precipitation. Ecosphere 9:e02166

Jacobs AC, Fair JM, Zuk M (2015) Coloration, paternity, and assortative mating in western bluebirds. Ethology 121:176-186

Johnson K, Sadoti G, Smith J (2017) Weather-induced declines in piñon tree condition and response of a declining bird species. J Arid Environ 146:1-9

Kalies EL, Rosenstock SS (2013) Stand structure and breeding birds: implications for restoring ponderosa pine forests. J Wildl Manag 77:1157-1165

Keppel G, Van Niel KP, Wardell-Johnson GW, Yates CJ, Byrne M, Mucina L, Schut AG, Hopper SD, Franklin SE (2012) Refugia: 
identifying and understanding safe havens for biodiversity under climate change. Glob Ecol Biogeogr 21:393-404

Lack D (1947) The significance of clutch-size. Ibis 89:302-352.

Lack D (1948) The significance of clutch-size. Part III.- Some Interspecific Comparisons. Ibis 90:25-45.

Louisiana State University, Southern Regional Climate Center: Climate Information Data Portal (2018) https://climdata.srcc.lsu.edu. Accessed 26 June 2018

Maggini R, Lehmann A, Kery M, Schmid H, Beniston M, Jenni L, Zbinden N (2011) Are Swiss birds tracking climate change? Detecting elevational shifts using response curve shapes. Ecol Model 222:21-32

McCarty JP (2001) Ecological consequences of recent climate change. Conserv Biol 15:320-331

McDowell NG, Allen CD (2015) Darcy's law predicts widespread forest mortality under climate warming. Nat Clim Chang 5:669-672

McKellar AE, Marra PP, Hannon SJ, Studds CE, Ratcliffe LM (2013) Winter rainfall predicts phenololgy in widely separated populations of a migrant songbird. Oecologia 172:595-605

McLeod AI (2011) Kendall: Kendall rank correlation and Mann-Kendall trend test. R package version 2.2. https://CRAN.R-project.org/ package $=$ Kendall

Melillo JM, Richmond T, Yohe G Eds (2014) Highlights of climate change impacts in the United States: The Third National Climate Assessment. U.S. Global Change Research Program. doi:https://doi. org/10.7930/J08G8HMN

NOAA National Centers for Environmental Information (2018) Climate at a glance: divisional time series. https://www.ncdc.noaa.gov/cag. Accessed 18 June 2018

Nussey DH, Postma E, Gienapp P, Visser ME (2005) Selection on heritable phenotypic plasticity in a wild bird population. Science 310 : 304-306

Oswald BP, Dugan SC, Balice RG, Unger DR (2016) Overstory tree mortality in Ponderosa Pine and Spruce-Fir ecosystems following a drought in Northern New Mexico. Forests 7:225

Perrins CM (1970) The timing of birds' breeding seasons. Ibis 112:242255

R Core Development Team (2018) R: a language and environment for statistical computing. R Foundation for Statistical Computing. Vienna, Austria. https://www.R-project.org/

Radchuk V, Reed T, Teplitsky C, van de Pol M, Charmantier A, Hassall C, Adamík P, Adriaensen F, Ahola MP, Arcese P, Avilés JM et al (2019) Adaptive responses of animals to climate change are most likely insufficient. Nat Commun 10:3109

Root TL, Price JT, Hall KR, Schneider SH, Rosenzweig C, Pounds JA (2003) Fingerprints of global warming on wild animals and plants. Nature 421:57-60

Sanz JJ (2002) Climate change and breeding parameters on great and blue tits throughout the western Palaearctic. Glob Chang Biol 8:409-422

Sanz JJ, Potti J, Moreno J, Merino S, Frías O (2003) Climate change and fitness components of a migratory bird breeding in the Mediterranean region. Global Change Biol 9:461-472.

Saracco J, Siegel R, Helton L, Stock S, DeSante D (2018) Phenology and productivity in a montane bird assemblage: trends and responses to elevation and climate variation. Glob Chang Biol 2019:1-12
Sauer J, Link W, Fallon J, Pardieck K, Ziolkowski D Jr (2013) North American breeding bird survey 1966-2011: summary analysis and species accounts. North Am Fauna 79:1-32

Sekercioglu CH, Schneider SH, Fay JP, Loarie SR (2008) Climate change, elevational range shifts, and bird extinctions. Conserv Biol $22: 140-150$

Socolar JB, Epanchin PN, Beissinger SR, Tingley MW (2017) Phenological shifts conserve thermal niches in North American birds and reshape expectations for climate-driven range shifts. Proc Natl Acad Sci USA 114:12976-12981

Stenseth N, Mysterud A, Ottersen G, Hurrell J, Chan KS, Lima M (2002) Ecological effects of climate fluctuations. Science 297:1292-1296

Stephens PA, Mason LR, Green RE, Gregory RD, Sauer JR, Alison J, Aunins A, Brotons L, Butchart SHM, Campedelli T, Chodkiewicz T, Chylarecki P, Crowe O, Elts J, Escandell V, Foppen RPB, Heldbjerg H, Herrando S, Husby M, Jiguet F, Lehikoinen A, Lindstrom A, Noble DG, Paquet JY, Reif J, Sattler T, Szep T, Teufelbauer N, Trautmann S, van Strien AJ, van Turnhout CAM, Vorisek P, Willis SG (2016) Consistent response of bird populations to climate change on two continents. Science 352:84-87

Tingley MW, Koo MS, Moritz C, Rush AC, Beissinger SR (2012) The push and pull of climate change causes heterogeneous shifts in avian elevational ranges. Glob Chang Biol 18:3279-3290

Torti V, Dunn P (2005) Variable effects of climate change on six species of North American birds. Oecologia 145:486-495

Vedder O (2012) Individual birds advance offspring hatching in response to increased temperature after the start of laying. Oecologia 170: 619-628

Visser M, Adriaensen F, van Balen J, Blondel J, Dhondt A, van Dongen S, du Feu C et al (2003) Variable responses to large-scale climate change in European Parus populations. Proc R Soc Lond B 270: 367-372

Visser M, Holleman L, Gienapp P (2006) Shifts in caterpillar biomass phenology due to climate change and its impact on the breeding biology of an insectivorous bird. Oecologia 147:164-172

Whitehouse M, Harrison N, Mackenzie J, Hinsley S (2013) Preferred habitat of breeding birds may be compromised by climate change: unexpected effects of an exceptionally cold, wet spring. PLoS One 8:e75536

Wiens JJ, Graham CH (2005) Niche conservatism: integrating evolution, ecology, and conservation biology. Annu Rev Ecol Evol Syst 36: 519-539.

Wiens JJ, Ackerly DD, Allen AP, Anacker BL, Buckley LB, Cornell HV, Damschen EI, Davies TJ, Grytnes JA, Harrison SP, Hawkins BA (2010) Niche conservatism as an emerging principle in ecology and conservation biology. Ecol Lett 10:1310-1324

Williams SE, Shoo LP, Isaac JL, Hoffman AA, Langham G (2008) Towards an integrated framework for assessing the vulnerability of species to climate change. PLoS Biol 6:e325

Williams AP, Allen CD, Millar CI, Swetnam TW, Michaelson J, Still CJ, Leavitt SW (2010) Forest responses to increasing aridity and warmth in the southwestern United States. Proc Natl Acad Sci USA 107:21289-21294

Publisher's note Springer Nature remains neutral with regard to jurisdictional claims in published maps and institutional affiliations. 